John Carroll University

Carroll Collected

Sociology

2012

\title{
Maintaining friendships in early stage dementia: Factors to consider
}

Phyllis Braudy Harris

JohnCarroll University, pharris@jcu.edu

Follow this and additional works at: http://collected.jcu.edu/soc-facpub

Part of the Family, Life Course, and Society Commons, and the Medicine and Health Commons

\section{Recommended Citation}

Harris, Phyllis Braudy, "Maintaining friendships in early stage dementia: Factors to consider" (2012). Sociology. 3.

http://collected.jcu.edu/soc-facpub/3

This Article is brought to you for free and open access by Carroll Collected. It has been accepted for inclusion in Sociology by an authorized administrator of Carroll Collected. For more information, please contact connell@jcu.edu. 


\title{
Maintaining friendships in early stage dementia: Factors to consider
}

\author{
Phyllis Braudy Harris
}

John Carroll University, USA

\begin{abstract}
Friendships and the importance of social connectiveness play a critical role in aging well, regardless of gender, race, social class, or impairment. Yet, dementia takes its toll on social relationships, and many friends withdraw and 'disappear', because they can no longer bear to see the changes that are taking place in their diagnosed friend. The dementia care literature documents this abandonment; however, this study examines the opposite occurrence. In order to understand more clearly the role of long-term friendships and how such friendships remain and continue, despite the diagnosis of dementia, this qualitative study examines in depth eight people in the early stages of dementia who have been able to maintain strong friendships despite the diagnosis. Factors that seem to play important roles are: (I) the importance of the friendships, (2) factors affecting the quality of the relationships, (3) mutually beneficial relationships, (4) core values, (5) acceptance and disclosure, and (6) recognition of strengths and understanding of limitations.
\end{abstract}

\section{Keywords}

Alzheimer's disease, dementia, friendships, social relationships, subjective experience of dementia

\section{Introduction}

'Don't walk behind me; I may not lead. Don't walk in front of me; I may not follow. Just walk beside me and be my friend.' (Albert Camus)

Friendship is a term that is difficult to define and has many meanings from the literary quote above to social scientists who try to define, measure, and quantify it with psychometric scales of perceived social support or felt social isolation (Hawthorne, 2006; Wilks, 2009). No matter how defined, friendship is an integral and meaningful part of the human experience. Yet, what happens to friendships during the course of dementia is that dementia takes its toll on social relationships, and many friends withdraw and 'disappear', because they can no longer bear to see the changes that are taking place in their 
diagnosed friend. The dementia care literature documents this abandonment; however, this study exams the opposite occurrence. This research seeks to elucidate the role of long-term friendships and how such friendships remain and continue, despite the diagnosis of dementia.

The presence (or lack) of friends in one's life has been documented to have a significant impact beyond just the importance of having a confidant with whom to talk. Studies have shown that the lack of friendship (social isolation) can affect physical health. Social isolation is associated with poor health-related quality of life, poorer health status, and poorer outcomes from surgical procedures such as cardiovascular surgery (Cantor and Sanderson, 1999; Farmer et al., 1996; Hawthorne, 2006; Ruberman, Weinblatt, Goldberg, \& Chaudhary, 1984). Also there are associations between social isolation and mental illness, depression, suicide, and premature death (Ellis and Hickie, 2001; Fratiglioni, Wang, Ericsson, Maytan, \& Winblad, 2000; House, Robbins, \& Metzner, 1982; Kawachi et al., 1996; Lester \& Young, 1992; Rokach, 2000). As dementia progresses, it is very common for friends to withdraw and sever their friendship ties with their friends who have been diagnosed, adding to the diagnosed person's feelings of depression, abandonment, and 'otherness' (Harris, 2004; Harris \& Keady, 2004; Lauer, 2007; Ostwald \& Hepburn, 2002; Snyder, 1999; Sterin, 2002; Taylor, 2007).

However, friendships and other types of social support have been found to have a positive impact on the dementia experience. Establishing friendships in long-term care settings can help residents with dementia maintain a sense of identity and purpose (Williams \& Roberts, 1995) and lessen agitation (Kutner, Stavisky, Clark, \& Green, 2000). Having close social connections with friends and family can act as a protective factor against some of the devastating effects of dementia, physiologically, socially, as well as functionally (Bennett, Schneider, Tang, Arnold, \& Wilson, 2006; Ficker, MacNeill, Bank, \& Lichtenberg, 2002; Van Dijkhuizen, Clare, \& Pearce, 2006).

Yet, as the symptoms of dementia grow more severe, communication becomes more difficult, activities become more limited, moods become more labile, and judgment becomes impaired, all changes that can impede a friendship; and the two friends who used to be on equal footing are now no longer equal. Still, however, the core self and values of the person remain, though they may be harder to reach and understand (Bell \& Troxel, 2003; Fazio \& Mitchell, 2009; Harris \& Sterin, 1999; Sabat, 2001). Thus, the need for 'true friends' may become even more important for people with dementia, as they struggle to maintain their sense of self. This study focuses on the friendships that remain, those longstanding friendships, and seeks to answer two main research questions.

(1) Do remaining friendships have a meaningful impact on the experience of early stage dementia?

(2) What factors are crucial to the retention of those friendships?

\section{Methods}

\section{Design}

A grounded theory approach was chosen to provide an in-depth understanding of the subjective experience of people with early stage dementia and their friend relationships, primarily drawing on the work of Glaser and Strauss (1967) and Glaser (1978). As a 
qualitative phenomenological method, grounded theory is particularly useful when there is limited knowledge about a phenomenon. This means that an inductive approach is used that begins with individual experiences and findings that are grounded in this specific context (Glaser \& Strauss, 1967). Thus, in the context of the reported study, the words of the participants are used to explain the impact of dementia on their remaining friendships and how those friendship connections are able to be maintained.

\section{Data collection}

This is a purposive sample of eight cases that was drawn from a larger study that examined the experience of a person living with early stage dementia. Thus, the original study was not directly focused on friendship. Data were collected through in-depth interviews with people with early stage Alzheimer's disease (AD) or related dementias, who were showing signs of memory loss. The researcher did not administer the Mini-Mental State Examination (MMSE). Diagnosis was made by the geriatric assessment units of local hospitals, and then individuals and their families were referred to the Alzheimer's Association's early stage programs. Before the study commenced, the research was approved by the University Institutional Review Board for the Protection of Human Subjects.

The participants were recruited through a chapter of the Alzheimer's Association. A social worker from the Association, through an initial telephone conversation, gauged the interest of the person in participating in the study. If there was some tentative interest, the researcher followed-up with another phone call to the person to explain the study and answer questions. If there was a caregiver, the researcher also spoke with them, and obtained their verbal consent before interviewing the family member, although the person diagnosed made the final decision to participate in the study. Each person was interviewed in their own home, after the purpose of the study was explained again, and an informed consent form was read, discussed, and signed. The interviews took approximately 90 minutes. For those people who were the most insightful about and aware of their situation $(N=5)$, as determined by the observations of the researcher during the first interview and collaborated by the family member (if there was one involved), a follow-up interview was conducted 4-6 months later. All interviews were taped and transcribed verbatim within 2 weeks after the interview. The transcriptions were checked for accuracy against field notes completed immediately after each interview.

\section{Sample}

The criteria for sample selection were that a person had to have a diagnosis of early stage dementia, was evidencing signs of memory loss, and was aware of the situation. The most common diagnosis was early stage AD (87\%), and the mean number of years with the diagnosis was 3 years, with a range of 2-6 years. All of the eight participants were female; the mean age at the time of the study was 75 years with a range from 59 to 85 , and all were White. Everyone, except one person, was a high school graduate, and two people had completed graduate degrees. Their occupations varied from housewives and secretaries to teachers and social workers. 


\section{Limitations}

There are many limitations to a qualitative study. The sample is small and certainly does not comprise a representative sample of people in the early stages of dementia. This study also uses a cross-sectional collection of data to examine a dynamic process, the impact of a diagnosis of dementia on friendships. However, qualitative research makes no claim to be representative of the population it is examining. The purpose of this methodology is to present a more in-depth, diverse, and complex picture of a phenomenon than has been previously reported, and identify possible factors that need to be tested and confirmed in larger representative studies.

\section{Findings}

The analytical framework from which these narratives were examined was organized around the perspective of the person with dementia with regards to friendship. These themes emerged from the conversations about living with early stage dementia, not in direct response to specific questions asked about friendship. Six themes that emerged from the narratives were: (1) the importance of friendships, (2) factors affecting the quality of the relationships, (3) mutually beneficial relationships, (4) core values, (5) acceptance and disclosure, and (6) recognition of strengths and understanding of limitations.

\section{Theme I: Importance of friendships}

Throughout all of the eight narratives, the significance of having a friend, a confidant can clearly be heard.

One woman stated

'My life depends upon my friends. I really like people and not having people around and being by yourself is not good.'

Another woman explained

'My friends are still my good friends. And If I am going out with a friend or one calls me up, I get undepressed'.

A third woman said

'You must find a buddy you can trust, a good listener; you will need to talk'.

That need for meaningful social connectedness, a key component of aging well, was also evident for people with dementia. As mentioned earlier in the methods section, the discussion about the role of friends emerged from interviews about living with early stage dementia, not in direct response to specific questions asked about friendship. The people with dementia brought up this topic themselves, thus illustrating the importance of friendship in their lives. 


\section{Theme 2: Factors affecting the quality of the relationship}

There were numerous factors that the people with dementia discussed in their narratives that affected the quality of their relationship with their friends:

A woman explained:

'The key is being comfortable (with friends). They know what I need. They treat me just like normal.'

Another woman:

'My friends don't put me down. A lot of other people think I am crazy.'

A third woman:

'I make a lot of mistakes and my friends tell me and that is fine. But my but my friends don't tell me what to do.'

A fourth woman explained:

'When I go out to lunch or for coffee with my friend, it is important to me that I pay my share; we take turns paying. Now, I don't remember, but I know I can trust my friend to tell me when it is my turn. I know she wants to pick up the tab, but she knows how important it is to me.'

Another woman exclaimed:

'My friends can distinguish the difference between being being able to remember and being able to understand.'

None of the factors illustrated above (sharing a comfort level, feeling a sense of trust, being honest, feeling accepted and understood, and the ability of friends to look beyond flaws or disabilities) are novel qualities of friendships. Still, they were qualities in friendships that may sometimes be taken for granted, but are particularly meaningful for a person with dementia as these factors reinforce for the diagnosed individuals that they are still respected and valued as a person who has worth; they are not defined by a diagnosis. It often happens that when people receive a dementia diagnosis that label is now how they are viewed by others (Sabat, 2001; Sterin, 2002; Taylor, 2007).

\section{Theme 3: Mutually beneficial and reciprocal relationships}

A woman explained how she and her friends still enjoy similar activities:

'My friends, we have been through single parenting together, raising our children together, doing things as singles. We have tickets to the Broadway series for the last five years. And we have other groups, take short trips together; celebrate each other's birthdays. I have no worry about my friends dropping me. I certainly don't expect them to take care of me, but I was there for them when I was able. I feel fine with my friends, because I'm very accepted no matter what.' 
Another woman explains:

'I have three friends that we do things together and they pick me up. One doesn't cook any more, but I know she likes sweets, so every once in awhile I will make bread pudding or rice pudding. That way I can say thank you.'

A third woman states:

'I don't like going any place by myself. With my friend we go to movies and sit and watch TV and we just enjoy life's things together today, that's all.'

Despite a diagnosis of dementia, friends were still able to connect by sharing common activities that they enjoyed, and the person with dementia was still able (on whatever level) to make a contribution to that relationship. It was no longer a relationship of two people on equal footing in some ways, yet the person with dementia could feel that it was still a twoway relationship, that she could do something meaningful for her friend. Long-lasting friendships are based on a reciprocal relationship, as described in exchange theory (Dowd, 1975), where both parties are meaningful contributing partners to the relationship.

\section{Theme 4: Recognition of a person's core values}

One woman explained:

'I've taken care of a lot of people, my dad, my brother, my husband; taking care of people, it gives me [...]I feel real good about that, as long as I can do it. My friend and I help together with meals on wheels; we both like helping.'

Another woman stated:

'I would rather a friend wait until I ask for help, then help me. I would rather struggle and do it myself. Even if it takes me longer and it's a lot harder; I'd rather do it myself, as long as I can. I'm trying to hang on to what's left. My friend understands this.'

Although dementia can have a significant impact upon a person's communications skills and sense of self, core values of what truly defines a person can remain. The core values, in a sense, are essential to a person's self or personal identity. The friends in this study understood what was important to the diagnosed individual as a person; what was important to them so they could still be themselves, and they helped her to maintain those values. Above are two examples of these core values, for one person it was altruism, still being able to help another human being; for the other person, the need to remain independent was a core value.

\section{Theme 5: Acceptance and disclosure}

In order to move forward with this disease and gain some limited control, the person, as difficult as it is, must accept that they have such a diagnosis, not deny it (Harris \& Durkin, 2002; Harris \& Sterin, 1999; Oyebode, Motala, Hardy, \& Oliver, 2009).

A woman explained:

'You know one of the fundamentals in terms of living a good life, is accepting what you cannot control.' 
Another woman said:

'You have to change with it (AD) because if you don't change with it; you're going to be miserable. It's so much easier to say you have these limits.'

Another woman admitted:

'I've told all my good friends; and I think it is a big mistake not to tell people when you have this. Because they will wonder how come you don't remember this? And how come you are reacting this way. I think it is very important to tell all your friends. That's one of the things people with AD are apt to do and I think it is a big mistake.'

Although denial may be an ego defense mechanism and a way for some people to cope with the devastating news of the diagnosis (Clare, 2003), if a person cannot admit to having $\mathrm{AD}$ and be willing to disclose the diagnosis to the friend, then the friendship will be much more difficult to maintain. Friends will not understand that the changes in the person's behavior are due to the disease and attribute these changes to relationship-related issues or other incorrect interpretations, thus adding strain onto the relationship.

\section{Theme 6: Recognition of strengths and understanding of limitations}

On the one hand, the friends of the persons with dementia were still able to see the strengths that remained in the person. The friends valued those attributes and recognized the contribution the person could make. On the other hand, friends were realistic about the growing limitations of their diagnosed friends.

One woman exclaimed:

'I'm still active and I'm in a golf league and I get worse and worse every year and the girls in the league won't let me quit. They say I am a role model.'

Another woman stated:

'I am a member of a bereavement support group and I have been going for a few years. I have made a friend there. After the meetings, we would sit and talk. I like helping people and I am a good listener. It's developed into a wonderful relationship and he knows my situation. He now drives me to the group.'

Another woman, a former researcher stated:

'The trouble was that the things that interest me are intellectual things. I've never been good at anything else and intellectual requires memory. I mean there's just not getting around that. I wanted to do a research project on AD, you know from the inside out, but how could I? And then an old colleague came back into my life to help me make a new career, making scrambled eggs out of broken ones. Our friendship expanded into a collaboration. I could never imagine that my last research project would be a study of my own disease.'

\section{Discussion and conclusions}

Friendships are an important part of the human experience and can provide comfort, support and meaning to the lives of people with dementia, as evidenced from this study. Yet friendships, even in the early stages of dementia are often difficult to maintain, given the 
nature of dementia, with the changes it causes in individuals and social relationships (Phinney, 2002; Snyder, 2002). From a study on living with early stage dementia, focused on the perspective of the diagnosed person, people in their narratives, unsolicited and without probes, discussed friendships, thus illustrating how important these relationships are for them. From those discussions, factors began to emerge related to commonalities among their remaining friendships from the diagnosed person's perspective. Friendships that appear to remain and continue, both long-term friendships and newer ones, shared some common factors: (1) the person with dementia was willing to disclose the diagnosis to friends and on some level accepted the diagnosis; (2) friends could understand that the core values of the diagnosed individual had not changed and helped them maintain those core values; (3) friends focused on the remaining strengths, understood the limitations, and were able to work around them; (4) the otherwise healthy friends and the person with dementia realized that the relationship, although perhaps not as equal as it once was, could still be mutually rewarding for both; (5) friends were able to accept dementia as a disability and look beyond it, treating the person with dementia as a 'whole person'; and (6) friends valued the trust of the person with dementia and rarely violated that trust.

There appears to be no doubt from the data presented that the presence of friends can add to the quality of life of the person with dementia. Those relationships added richness, a sense of connectedness, caring, and comfort to the lives of people with dementia, as they do to the lives of many otherwise healthy people. In future research, it would be interesting to speak also to an identified friend, in order to understand from the friend's perspective if these six themes ring true, how this friendship affects their lives, and why they work on maintaining that friendship, which so many other people choose to let 'wither on the vine'. The gathering of such information could lead to the development of educational models on maintaining friendship that could improve the lives of people with dementia and those of their friends. Ultimately, the role of psychosocial research in dementia is to better understand the consequences of living with the disease, in order to improve the quality of life for the person and caregiver (Harris, 2010). As one man with AD told this researcher over a decade ago: 'I'm dying with Alzheimer's disease. I know that ... What you need to do what they [researchers] need to do - is help me figure out how to live with it' (Harris, 2002, p. xiii). A better understanding of the role of long-term friendships and how to maintain them is an area of research that has been overlooked far too long in the dementia care literature, even though the maintenance of long-term friendships would help the diagnosed person live better with their condition.

\section{References}

Bell, V., \& Toxel, D. (2003). The Best Friends Approach to Alzheimer's care. Baltimore, MD: Health Professions Press.

Bennett, D., Schneider, J. A., Tang, Y., Arnold, S. E., \& Wilson, R. S. (2006). The effect of social networks on the relation between Alzheimer's disease pathology and level of cognitive function in old people: a longitudinal cohort study. Lancet Neurology, 5, 406-412.

Cantor, N., \& Sanderson, C. (1999). Life task participants and well-being: The importance of taking part in daily life. In D. Kahnemann, E. Diener, \& N. Schwartz (Eds.), Well-being: The foundations of heonic psychology (pp. 230-243). New York: Russell Sage Foundation.

Clare, L. (2003). Managing threats to self: Awareness in early stage Alzheimer's disease. Social Science and Medicine, 57, 1017-1029.

Dowd, J. J. (1975). Aging as exchange: A preface to theory. The Journal of Gerontology, 30, 584-594. 
Ellis, P., \& Hickie, I. (2001). What causes mental illness? In S. Bloch, \& B. Singh (Eds.), Foundations of clinical psychiatry (pp. 43-62). Melbourne: Melbourne University Press.

Farmer, I., Meyer, P., Ramsey, D., Goff, D., Wear, M., Labarthe, D., et al. (1996). Higher levels of social support predict greater survival following acute myocardial infarction. The Corpus Christi Heart Project. Behavioural Medicine, 22, 59-66.

Fazio, S., \& Mitchell, D. (2009). Persistence of self in individuals with Alzheimer's disease: Evidence from language and visual recognition. Dementia: The International Journal of Social Research and Practice, 8, 39.

Fratiglioni, L., Wang, H., Ericsson, K., Maytan, M., \& Winblad, B. (2000). Influence of social networks on the occurrence of dementia: A community-based longitudinal study. The Lancet, 355, 1315-1319.

Ficker, L. J., MacNeill, S. E., Bank, A. L., \& Lichtenberg, P. A. (2002). Cognition and perceived social support among live-alone urban elderly. Journal of Applied Gerontology, 21, 437-451.

Glaser, B. G. (1978). Theoretical sensitivity. Mill Valley, CA: Sociology Press.

Glaser, B. G., \& Strauss, A. L. (1967). The discovery of grounded theory: Strategies for qualitative research. Chicago, IL: Aldine.

Harris, P. B. (Ed) (2002). The person with Alzheimer's disease: Pathways to understanding the person. Baltimore: The Johns Hopkins University Press.

Harris, P. B. (2004). The perspective of younger people with dementia: Still an overlooked population. Social Work in Mental Health, 2, 17-36.

Harris, P. B. (2010). Dementia and dementia care: The contributions of a psychosocial perspective. Sociology Compass, 4, 249-262.

Harris, P. B., \& Durkin, C. (2002). Building resilience through coping and adapting. In P. B. Harris (Ed.), The person with Alzheimer's disease: Pathways to understanding the experience (pp. 165-184). Baltimore, MD: The John Hopkins University Press.

Harris, P. B., \& Keady, J. (2004). Living with early on-set dementia: Exploring the experience and developing evidence-based guidelines for practice. Alzheimer's Care Quarterly, 5, 111-122.

Harris, P. B., \& Sterin, G. J. (1999). Insider's Perspective: Defining and preserving the self in dementia. Journal of Aging and Mental Health, 5, 241-256.

Hawthorne, G. (2006). Measuring social isolation in older adults: Development and initial validation of the friendship scale. Social Indicators Research, 77, 521-548.

House, J., Robbins, C., \& Metzner, H. (1982). The association of social relationships and activities with mortality. American Journal of Epidemiology, 116, 123-140.

Kawachi, I., Colditz, G., Ascherio, A., Rimm, E., Giovannucci, E., Stampfer, M., et al. (1996). A prospective study of social networks in relation to total mortality and cardiovascular disease in men in the USA. Journal of Epidemiology and Community Health, 50, 245-251.

Kutner, N. G., Stavisky, R. C., Clark, W. S., \& Green, R. C. (2002). Friendship interactions and expression of agitation among residents of a dementia care unit. Research and Aging, 22, 188-205.

Lauer, C. S. (2007). A friend in need. Modern Health Care, 37(48), 1-2.

Lester, D., \& Young, B. (1992). Social and economic correlates of elderly suicide rate. Suicide and Life Threatening Behaviors, 22, 36-47.

Ostwald, S. K., \& Hepburn, K. W. (2002). Stress of dementia: View from the inside. American Journal of Alzheimer's Disease and Other Dementias, 17, 303-312.

Oyebode, J. R., Motala, J. R., Hardy, R. M., \& Oliver, C. (2009). Coping with challenges to memory in people with mild to moderate Alzheimer's disease: Observation of behavior in response to analogues of everyday situations. Aging \& Mental Health, 13, 46-53.

Phinney, A. (2002). Living with the symptoms of Alzheimer's disease. In P. B. Harris (Ed.), The person with Alzheimer's disease: Pathways to understanding the experience (pp. 49-74). Baltimore, MD: The John Hopkins University Press.

Rokach, A. (2000). Loneliness and the life cycle. Psychological Reports, 86, 629-642.

Ruberman, W., Weinblatt, E., Goldberg, J., \& Chaudhary, B. (1984). Psychological influences on mortality after myocardial infarction. New England Journal of Medicine, 311, 552-559. 
Sabat, S. R. (2001). The experience of Alzheimer's disease: Life through a tangled veil. Oxford: Blackwell Publishers.

Snyder, L. (1999). Speaking our minds: Personal reflections from individuals with Alzheimer's disease. New York: W.H. Freeman.

Snyder, L. (2002). Social and family relationships: Establishing and maintaining connections. In P. B. Harris (Ed.), The person with Alzheimer's disease: Pathways to understanding the experience (pp. 112-133). Baltimore, MD: The John Hopkins University Press.

Sterin, G. J. (2002). Essay on a word: A lived experience of Alzheimer's disease. Dementia: the International Journal of Social Research and Practice, 1, 7-10.

Taylor, R. (2007). Alzheimer's from the inside out. Baltimore, MD: Health Professionals Press.

Van Dijkhuizen, M., Clare, L., \& Pearce, A. (2006). Striving for connection. Dementia: The International Journal of Social Research and Practice, 5, 73-94.

Wilks, S. E. (2009). Support for Alzheimer's caregivers: Psychometric evaluation of familial friend support measures. Research on Social Work Practice, 19, 722-729.

Williams, B., \& Roberts, P. (1995). Friends in passing: Social Interaction at an adult day care center. International Journal of Aging and Human Development, 41, 63-78.

Phyllis Braudy Harris, PhD, LISW, ACSW is Professor and Chair of the Sociology Department and Director of the Aging Studies at John Carroll University, Cleveland, Ohio. She is a Fellow of the Gerontological Society of America, the 2008 Gerontological Educator of the year for the state of Ohio, and is a founding co-editor of Dementia: The International Journal of Social Research and Practice. Her research interest lies in understanding the psychosocial impact of a dementing illness on family members and persons living with early stage dementia. She has published two books, written numerous book chapters and articles in leading gerontology journals, and presents nationally and internationally on dementia care. 